\title{
National survey of emergency physicians for transient ischemic attack (TIA) risk stratification consensus and appropriate treatment for a given level of risk
}

\author{
Jeffrey J. Perry, MD, MSc* ${ }^{\dagger \ddagger}$; Justin H. Losier, MD ${ }^{\dagger \ddagger}$; Ian G. Stiell, MD, MSc* ${ }^{\dagger \ddagger}$; Mukul Sharma, MD, \\ $\mathrm{MSc}^{\S}$; Kasim Abdulaziz, $\mathrm{MSc}^{*}$
}

\begin{abstract}
Introduction: Five percent of transient ischemic attack (TIA) patients have a subsequent stroke within 7 days. The Canadian TIA Score uses clinical findings to calculate the subsequent stroke risk within 7 days. Our objectives were to assess 1) anticipated use; 2) component face validity; 3 ) risk strata for stroke within 7 days; and 4) actions required, for a given risk for subsequent stroke.

Methods: After a rigorous development process, a survey questionnaire was administered to a random sample of 300 emergency physicians selected from those registered in a national medical directory. The surveys were distributed using a modified Dillman technique.

Results: From a total of 271 eligible surveys, we received 131 $(48.3 \%)$ completed surveys; $96.2 \%$ of emergency physicians would use a validated Canadian TIA Score; 8 of 13 components comprising the Canadian TIA Score were rated as Very Important or Important by survey respondents. Risk categories for subsequent stroke were defined as minimalrisk: $<1 \%$; low-risk: $1 \%-4.9 \%$; high-risk $5 \%-10 \%$; critical-risk: $>10 \%$ risk of subsequent stroke within 7 days.

Conclusion: A validated Canadian TIA Score will likely be used by emergency physicians. Most components of the TIA Score have high face validity. Risk strata are definable, which may allow physicians to determine immediate actions, based on subsequent stroke risk, in the emergency department.
\end{abstract}

\section{RÉSUMÉ}

Introduction: Cinq pour cent des accidents ischémiques transitoires (AIT) se soldent par la survenue d'un accident vasculaire cérébral (AVC) dans les 7 jours suivants; l'échelle canadienne prévisionnelle du risque d'AVC après un AIT ("Canadian TIA Score "), qui repose sur des caractéristiques cliniques, permet de calculer ce risque d'accident. L'étude visait à évaluer: 1) I'utilisation future de l'instrument; 2) la validité apparente de ses éléments; 3 ) les catégories de risque
d'AVC dans les 7 jours suivants; et 4) les mesures à prendre en fonction du risque d'AVC ultérieur.

Méthode: Après un processus rigoureux d'élaboration, un questionnaire d'enquête a été envoyé à un échantillon aléatoire de 300 médecins d'urgence inscrits dans le répertoire national. Le questionnaire a été distribué selon une version modifiée de la méthode de Dillman.

Résultats: Ont été reçus 131 (48,3\%) questionnaires d'enquête remplis sur un total de 271 jugés recevables. Dans I'ensemble, 96,2\% des médecins d'urgence ont indiqué qu'ils utiliseraient une échelle canadienne validée. Huit caractéristiques sur treize incluses dans l'échelle canadienne étaient considérées comme un élément "Très important " ou " Important " par les répondants au questionnaire. Les catégories de risque d'AVC ultérieur au cours des 7 jours suivants ont été établies comme suit: risque minime: $<1 \%$; risque faible: $1 \%-4,9 \%$; risque élevé: $5 \%-10 \%$; risque très élevé: $>10 \%$.

Conclusions: II est probable que les médecins d'urgence utilisent un instrument canadien validé d'évaluation du risque d'AVC après un AIT. La plupart des caractéristiques incluses dans l'échelle ont une bonne validité apparente. Les classes de risque étant définies, les médecins peuvent prendre des mesures immédiates, en fonction du risque d'AVC ultérieur, au service des urgences.

Key words: clinical decision rules, stroke, transient ischemic attack

\section{INTRODUCTION}

The World Health Organization (WHO) defines transient ischemic attack (TIA) as a sudden, focal neurological deficit lasting for less than 24 hours, presumed to be of vascular origin, and confined to an area of the

From the *Department of Epidemiology and Community Medicine, University of Ottawa, Ottawa, ON; †Clinical Epidemiology Program, Ottawa Hospital Research Institute, Ottawa, ON; ‡Department of Emergency Medicine, University of Ottawa, Ottawa, ON; and §Department of Neurology, McMaster University, Hamilton, ON.

Correspondence to: Dr. Jeffrey J. Perry, Clinical Epidemiology Program, F6, The Ottawa Hospital, Civic Campus, 1053 Carling Avenue, Ottawa, ON K1Y 4E9; Email: jperry@ohri.ca 
brain or eye perfused by a specific artery. ${ }^{1,2}$ TIAs are relatively common, having an annual incidence of 68 per $100,000 .^{3}$ Although relatively benign, given that TIAs cause temporary neurological deficits, they are important because they identify individuals at high risk of subsequent stroke. Previous studies have estimated this risk to be $4 \%-10 \%$ within 7 days of TIA, and increases to $8 \%-12 \%$ by 90 days. $^{3-12}$

Stroke is a serious and significant health and economic burden, because it is the leading cause of adult disability, the second leading cause of dementia, and the third leading cause of death. ${ }^{13-15}$ In addition, it results in the use of large amounts of health care system resources. ${ }^{16}$ Effective prevention targeting those at greatest risk can be expected to provide individual and system benefits.

The ABCD2 Score (age, blood pressure, clinical features, duration of symptoms, and diabetes) developed by Johnston et al. has been used to help identify patients having a TIA who are at high risk of stroke. ${ }^{17-22}$ Unfortunately, the ACBD2 Score has not performed well in prospective validation (c-statistic: 0.56$).{ }^{23} \mathrm{We}$ recently conducted a prospective, multicentre study to determine clinical features of TIA patients presenting to emergency departments (EDs), associated with high risk of stroke and to develop a new clinical prediction score for impending stroke. ${ }^{24}$ The Canadian TIA Score consists of 13 variables, identifies the risk of subsequent stroke $\leq 7$ days, and quantifies the impending stroke risk following an ED visit for a new TIA.

The objectives of the current study were to assess emergency physician opinions regarding the following: 1) assess their anticipated use of the Canadian TIA Score by emergency physicians; 2) assess the Canadian TIA Score's component face validity; 3) define the risk strata for stroke within 7 days, and 4) assess the actions required for the Canadian TIA Score dependent upon level of risk for subsequent stroke.

\section{METHODS}

\section{Study design and participants}

This study was a postal survey of emergency physicians in Canada. To be considered for the study, physicians must have been practicing emergency medicine and seeing adult patients. A random sample of 300 emergency physicians was selected from a total of 2,450 registered in the Canadian Medical Directory. A \$10 coffee card was given with the first survey to all of the physicians.

\section{Outcome measures}

The primary objective for the survey was to determine the optimal cut-points for creating minimal, low, high, or critical risk strata for subsequent stroke within 7 days following TIA diagnosis. We were interested in determining the optimal cut-points that the majority $(75 \%)$ of emergency physicians would be satisfied with (i.e., the 25 th percentile). This percentile was chosen a priori by the study team as a pragmatic value that would include $75 \%$ of respondents, whereas the median would satisfy only half of the respondents. This study also investigated physicians' opinions on the Canadian TIA Score's component face validity and the management for TIA patients at each risk strata for subsequent stroke within 7 days of TIA diagnosis.

\section{Questionnaire development}

We followed the well-known Dillman's Tailored Design technique for the design of the survey. ${ }^{25}$ To aid the development of the final survey questionnaire, the survey was developed in three stages: 1) key informant, in-person interviews (pre-survey), 2) cognitive interviews (draft survey), and 3) pilot-testing (final draft survey). The key informant and cognitive interviews were conducted on convenience samples of neurologists and emergency physicians. Key informant interviews (pre-survey) were conducted to establish feasibility of the survey, obtain current knowledge of physicians on TIA, and determine ideal methods on gathering information for the components of the TIA as well as the risk strata. Clarity, comprehensibility, and face validity of the draft survey were evaluated through cognitive interviews. The cognitive interviews were conducted by providing the questionnaire to the physicians and asking them to read aloud their thoughts while completing the survey. In addition, their body language such as facial expressions, pauses, and referrals to previously completed questions were observed and clarified. The pilot survey (final draft survey) was conducted to identify and address any potential problems with our survey implementation procedure or the questionnaire.

The final questionnaire consisted of five sections with a total of 44 questions, and was printed on two 
single-sided pages (Appendix). The questionnaire consisted of an eligibility question (1 item), demographic and practice setting items (6 items), components of the proposed Canadian TIA Score (13 items), usage of the Canadian TIA Score (1 item), management for TIA patients at each risk strata (19 items), and optimal cutpoints for the risk strata (4 items). The cut-points were asked as open-ended percentage questions. The survey materials (final questionnaires, pre-notification letters, and cover letters) were translated by a trained medical translator into French for the French-speaking physicians as identified by the language of correspondence indicator in the Canadian Medical Directory. ${ }^{26}$

\section{Survey administration}

We mailed the final survey questionnaire to all 300 English and French-speaking emergency physicians in our sample. A pre-notification letter was sent out to all 300 physicians explaining that they had been selected to receive a survey and the importance of their input. A week later, the survey packages consisting of a cover letter, a questionnaire, a prepaid business reply mail envelope, and a coffee card were mailed to all of the physicians. Reminders along with a replacement questionnaire were mailed to the non-respondents every 3 weeks. The final reminder was mailed using Canpar courier service.

The researchers coordinating this study were located at the Ottawa Hospital Research Institute in Ottawa, ON. This study was approved by the Ottawa Health Science Network Research Ethics Board.

\section{Data analysis}

Descriptive statistics were used to summarize emergency physician responses. The four possible responses (very important, important, less important, and never important) on the components of the Canadian TIA Score were dichotomized as important (very important or important) or not (less important or never important). The four possible responses (yes, likely, unlikely, no) on whether the physicians will incorporate the proposed Canadian TIA Score in their clinical practice were dichotomized as yes (yes or likely) and no (unlikely or no). The optimal cut-points for the risk strata were presented using frequency distributions and box plots. The Canadian TIA Score's component face validity and management of TIA patients were presented using bar graphs. Data were analysed using SAS version 9.2 (SAS Institute, Cary, NC, USA).

\section{RESULTS}

\section{Respondents}

From a total of 300 emergency physicians surveyed, 10 were unreachable because they had moved, and 19 were ineligible because they were no longer practicing or were not seeing adult patients. We received 131 completed surveys from a total of 271 eligible physicians resulting in a response rate of $48.3 \%$.

Demographic information about the respondents is presented in Table 1. A significantly higher proportion (71.8\%) of respondents were male. The most common practice location was a teaching hospital $(50.4 \%$ of respondents) followed by community or district general hospitals with teaching ( $42.0 \%$ of respondents). More than $73.3 \%$ of the emergency physicians had been in practice for 10 or more years. A high proportion (96.2\%) of the emergency physicians indicated that they would use a validated Canadian TIA Score.

\section{Risk strata cut-points for subsequent stroke within seven days of TIA diagnosis}

Our results indicate that $75 \%$ of emergency physicians classified minimal risk as any cut-point below $1 \%$. Low risk was classified as a score from $1 \%$ to $4.9 \%$. High risk was classified as a score from $5 \%$ to $10 \%$. Critical risk was defined as any score above $10 \%$. These findings are summarized in Table 2.

The distribution of emergency physician responses on risk strata cut-points is presented in Figure 1. In general, there is less variability among the emergency physicians on the cut-points up to the low-risk strata. There is, however, a notable variability among the physicians on the cut-points at higher risk strata.

\section{Component face validity}

Figure 2 describes physician attitudes on the importance of select variables for the proposed stroke risk score, including the percentage rated as important for each. The results indicate that more than $75 \%$ of physicians thought that the following variables were important in the proposed stroke risk score: atrial 


\begin{tabular}{|c|c|}
\hline Characteristic & $\begin{array}{l}\text { \# (\%) of Respondents } \\
(\mathrm{N}=131)\end{array}$ \\
\hline \multicolumn{2}{|l|}{ Gender } \\
\hline Male & $94(71.8)$ \\
\hline Mean age (SD) & $45.0(8.4)$ \\
\hline \multicolumn{2}{|l|}{ Years in practice } \\
\hline$<10$ & $35(26.7)$ \\
\hline $10-19$ & $50(38.2)$ \\
\hline$\geq 20$ & $46(35.1)$ \\
\hline \multicolumn{2}{|l|}{ Years of residency training } \\
\hline$<3$ & $25(19.1)$ \\
\hline $3-5$ & $97(74.1)$ \\
\hline $5.5-9$ & $7(5.3)$ \\
\hline$\geq 10$ & $0(0)$ \\
\hline \multicolumn{2}{|l|}{ Practice setting } \\
\hline Teaching hospital & $66(50.4)$ \\
\hline $\begin{array}{l}\text { Community/district general hospital: } \\
\text { teaching }\end{array}$ & $55(42.0)$ \\
\hline $\begin{array}{l}\text { Community/district general hospital: } \\
\text { non-teaching }\end{array}$ & $9(6.9)$ \\
\hline Other & $1(0.8)$ \\
\hline \multicolumn{2}{|l|}{ Number of patients seen/week } \\
\hline$\leq 28$ & $2(1.5)$ \\
\hline $29-60$ & $19(14.5)$ \\
\hline $61-100$ & $69(52.7)$ \\
\hline$>100$ & $31(23.7)$ \\
\hline \multicolumn{2}{|l|}{ Province } \\
\hline Ontario & $48(36.6)$ \\
\hline Quebec & $27(20.6)$ \\
\hline British Columbia & $26(19.9)$ \\
\hline Alberta & $15(11.5)$ \\
\hline Manitoba & $4(3.1)$ \\
\hline New Brunswick & $3(2.3)$ \\
\hline Newfoundland and Labrador & $2(1.5)$ \\
\hline Nova Scotia & $2(1.5)$ \\
\hline Prince Edward Island & $2(1.5)$ \\
\hline Saskatchewan & $2(1.5)$ \\
\hline Yukon Territory & $0(0.0)$ \\
\hline Northwest Territories & $0(0.0)$ \\
\hline Nunavut & $0(0.0)$ \\
\hline
\end{tabular}

fibrillation on electrocardiogram (ECG), history of unilateral weakness, symptoms of first TIA lasted $\geq 10$ minutes, history or exam finding of dysarthria or aphasia (i.e., slurred speech or word finding problems), past medical history of carotid stenosis, infarction (old or new) on CT head, already on any antiplatelet therapy and first ever TIA. Fewer than $75 \%$ of physicians thought the following were important: history of gait disturbance, initial diastolic blood pressure at triage $\geq 110 \mathrm{~mm} \mathrm{Hg}$,
Table 2. Degree of risk accepted by $75 \%$ of physicians for subsequent stroke $\leq 7$ days

\begin{tabular}{lc} 
& Degree (\%) \\
\hline Minimal-risk & $<1$ \\
Low-risk & $1-4.9$ \\
High-risk & $5-10$ \\
Critical-risk & $>10$
\end{tabular}

glucose $\geq 15 \mathrm{mmol} / \mathrm{L}$, platelets $\geq 400 \times 10^{9} / \mathrm{L}$, and history of vertigo (as a negative predictor).

\section{Management given to patients}

Our results indicated that the investigations suggested by at least $75 \%$ of physicians for each risk stratum were as follows: minimal-risk: obtain an ECG today, obtain brain CT imaging as an outpatient, image the carotid arteries as an outpatient, obtain echocardiogram as an outpatient, and order an outpatient holter cardiac monitoring; low-risk: obtain an ECG today, image the carotid arteries as an outpatient, obtain echocardiogram as an outpatient, and order an outpatient holter cardiac monitoring; high-risk: obtain an ECG today, obtain brain CT imaging today, and put on cardiac monitor for $\geq 2$ hours today; critical-risk: obtain an ECG today, obtain brain CT imaging today, image the carotid arteries today, obtain echocardiogram today, and put on cardiac monitor for $\geq 2$ hours today. These findings are displayed in Figure 3.

In addition to maintaining a current antiplatelet agent or starting acetylsalicylic acid (ASA), recommended actions by at least $75 \%$ of physicians for each risk stratum were as follows: minimal-risk and low-risk: refer patient to rapid outpatient assessment with neurologist; highrisk: start or switch antiplatelet agent to clopidogrel or dipyridamole + ASA, start oral anticoagulation if in atrial fibrillation, start statin class medication, start or optimize control of hypertension, refer patient to neurology today; critical-risk: start or switch antiplatelet agent to clopidogrel or dipyridamole + ASA, start oral anticoagulation if in atrial fibrillation, start statin class medication, start or optimize control of hypertension, admit patient to hospital, and refer patient to neurology today. These findings are displayed in Figure 4. The percent of physicians who would report the patient to the ministry of transportation to suspend licence for each stratum were as follows: minimal-risk: $11.8 \%$; low-risk: $21.2 \%$; high-risk: 73.0; critical-risk: 100.0 . 


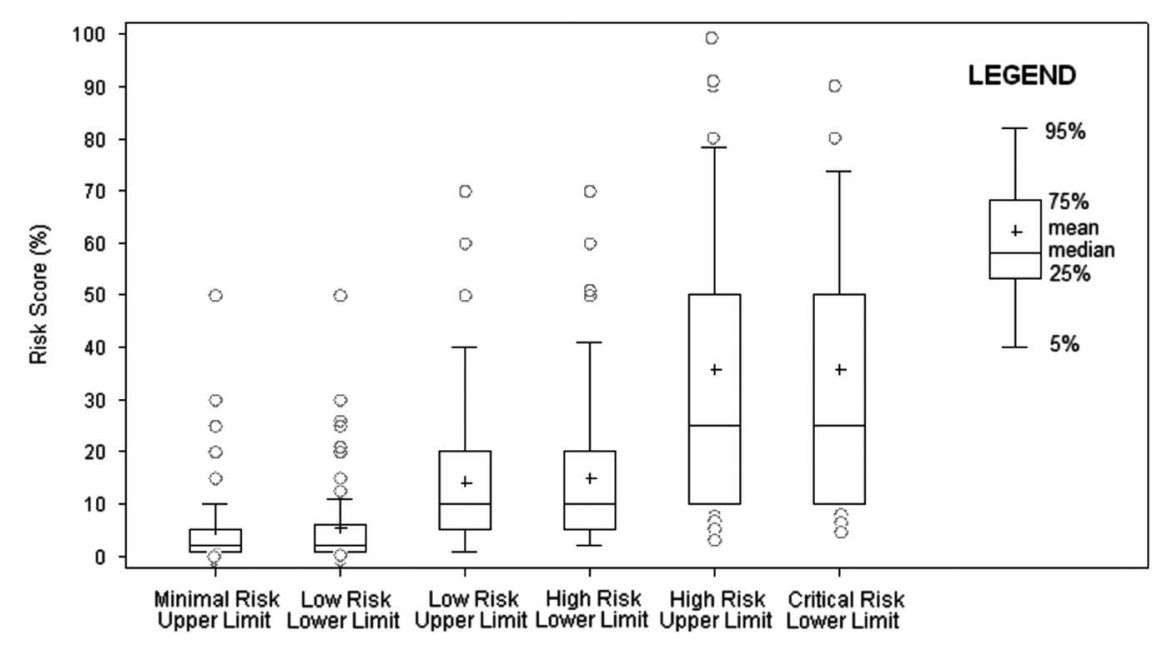

Figure 1. Distribution of Physician Responses on Optimal Cut-Points for Risk Strata.

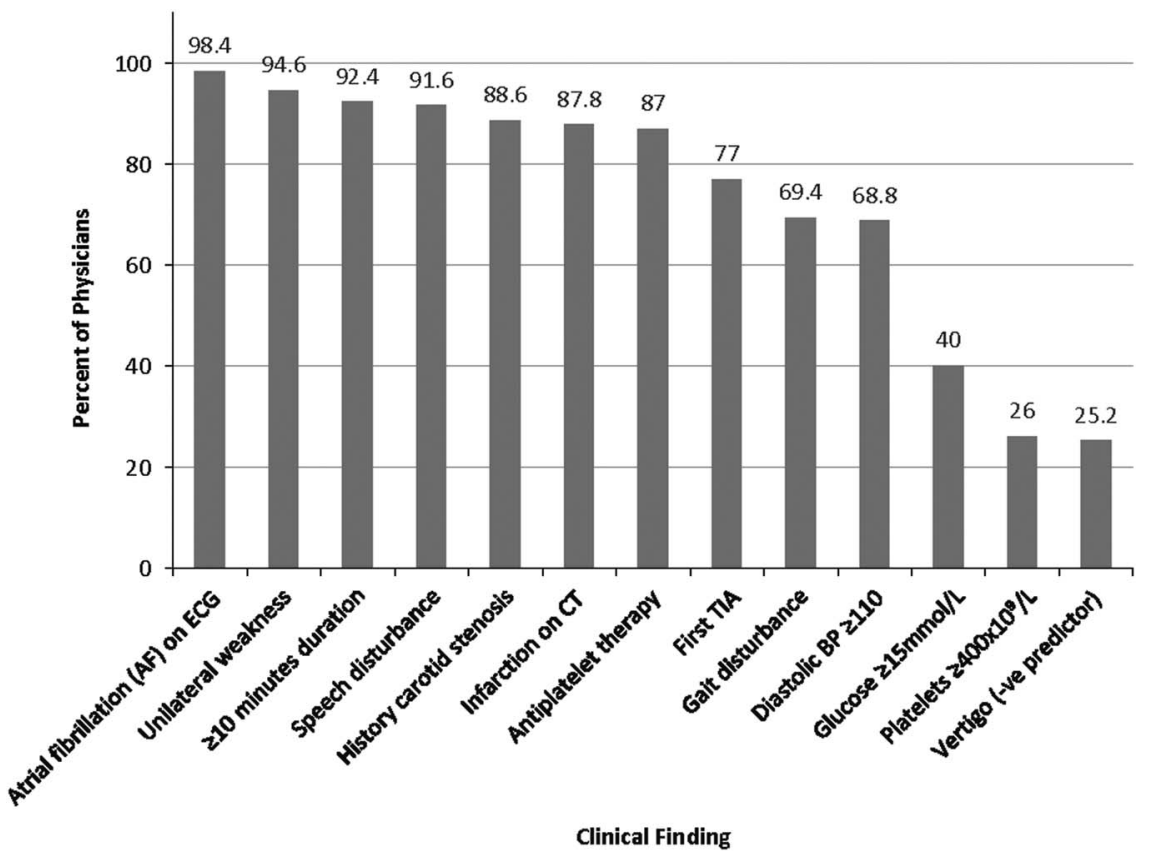

Figure 2. Physicians' views on the importance of select variables in the proposed stroke risk score.

\section{DISCUSSION}

We assessed emergency physician opinions on the proposed Canadian TIA Score to identify patients at high risk of stroke within 7 days of TIA diagnosis. This study shows that a high proportion of emergency physicians is likely to use a validated Canadian TIA Score.

The majority of emergency physicians consider most of the TIA Score's 13 variables as important. Not all of the variables received the same validity. In particular, elevated blood glucose, elevated platelets, and vertigo were less well-received by the emergency physicians. Although uncontrolled hyperglycemia has been previously demonstrated, it is uncertain whether physicians were less familiar with the risk, or if they were less comfortable with this specific cut-point. Likewise, it is well known that patients with thrombocythemia are at a higher risk of systemic thrombotic disorders, and physicians may have been less aware of this risk, or less comfortable with this specific cut-point. Finally, isolated 


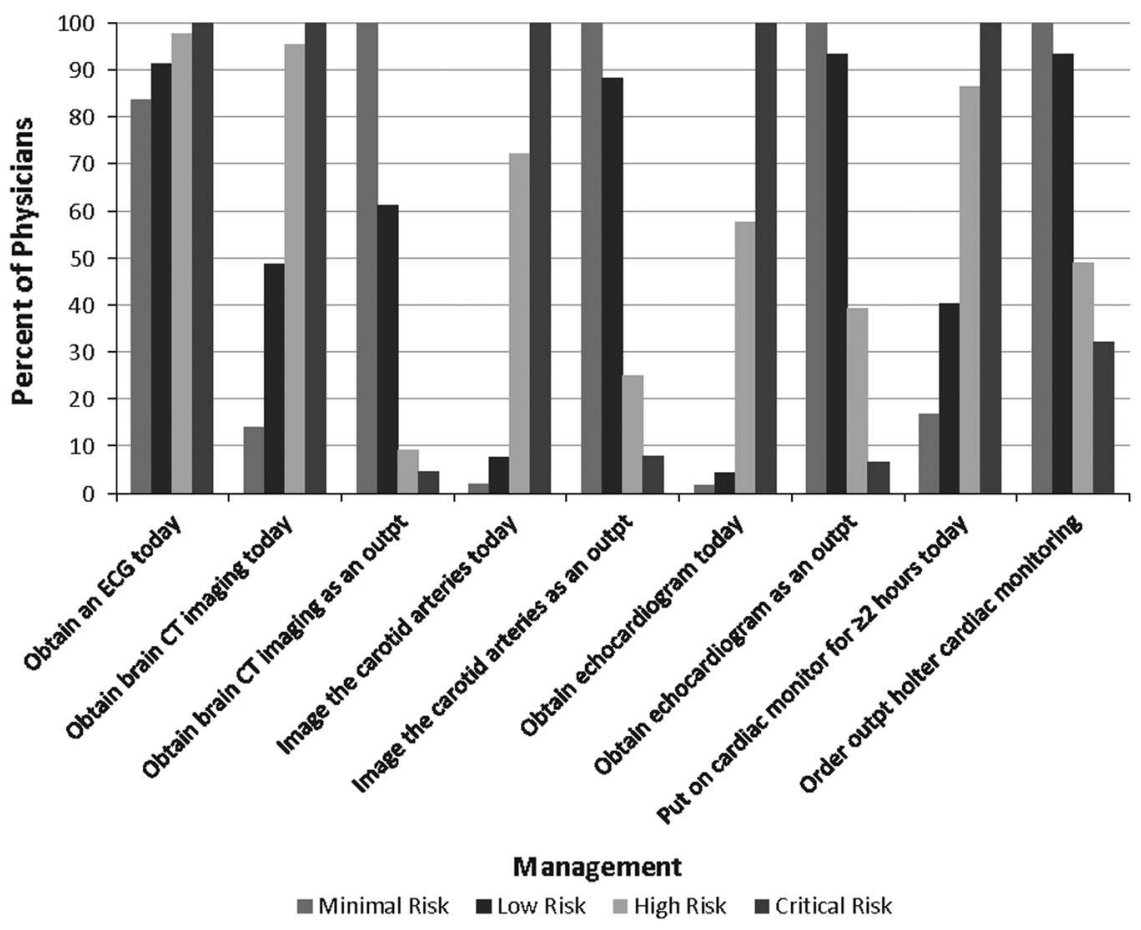

Figure 3. Physician responses on investigation chosen for patients for each stroke risk stratum.

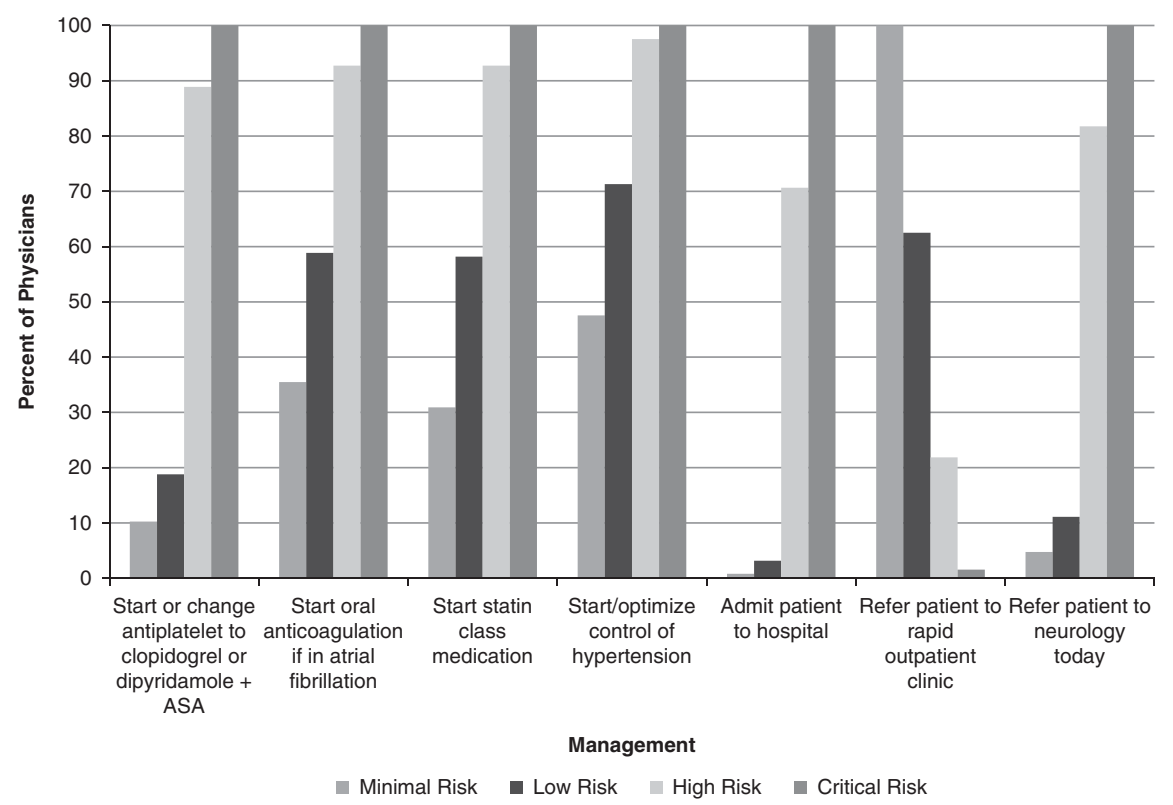

Figure 4. Physician Responses on Management Given to Patients for Each Stroke Risk Stratum.

vertigo is an extremely rare manifestation of TIA or stroke, physicians may not realize how rare isolated vertigo is as a presentation of stroke or TIA, or they may not have realized that patients with other findings besides vertigo will score at a higher risk level than those with isolated vertigo. Educational efforts may be needed if these elements are included in the final validated Canadian TIA Score.

The 2009 American Heart Association recommendations for managing TIA include 1) neuroimaging 
within 24 hours (preferably MRI) plus noninvasive imaging of the cervical vessels; 2) electrocardiography as soon as possible after TIA, with prolonged cardiac monitoring and echocardiography in patients in whom the etiology is not identified; 3) routine blood tests; and 4) hospitalization for patients presenting within 72 hours of TIA with an ABCD2 Score $>2$ (two). ${ }^{27}$

The current cut-point recommendation by the American Heart Association is an ABCD2 Score of 2 or more. Such a cut-point resulted in an excellent sensitivity for stroke at 7 days but poor specificity. ${ }^{23}$ According to these guidelines on managing suspected TIA patients, many resources would be used on patients not at risk for stroke, which is not pragmatic or costefficient to the health care system. Based on our survey results, physicians are able to define risk strata for impending stroke and have specific management recommendations for each. Therefore, if the Canadian TIA Score is used by emergency physicians, they may be able to more accurately identify those patients at greater risk and allocate health care resources in more effective and efficient ways.

The Canadian Best Practice Recommendations for Stroke Care (2013) suggest a variety of investigations and treatment modalities; however, they are not organized based on specific risk categories. Instead, these recommendations are broad. Physicians treating patients with suspected TIAs are advised to order basic blood work, including electrolytes, glucose, complete blood count (CBC), international normalized ratio (INR), activated partial thromboplastin time (aPTT), creatinine, glomerular filtration rate (GFR), blood urea nitrogen (BUN), lipid profile, liver panel, and troponin. For imaging, all patients are recommended to undergo ECG, chest x-ray, and immediate head CT or MRI if urgently available, as well as vascular imaging of the brain and neck arteries within 24 hours. In terms of acute blood pressure management, there are no definitive recommendations provided for patients presenting with suspected TIAs, because guidelines are listed for only patients who are presenting with suspected stroke. Blood glucose abnormalities should also be checked for and corrected, but, again, this was mentioned specifically for only patients who are presenting with suspected stroke. ${ }^{28}$ The Canadian Best Practice Guidelines appear to provide no graded recommendations for patients presented with TIAs. Instead, these are global recommendations, which leave physicians responsible for assessing level of risk for a stroke the patient presents with, in addition to selecting the most appropriate tests based on their own deductions. Given our survey results and proposed tool, physicians are able to define risk strata for impending stroke and have indicated suggested management recommendations for each stratum (i.e., given their knowledge and the existence of current evidence). If adopted into practice, our tool may help Canadian physicians better assess subsequent stroke risk, and this may assist physicians to determine how quickly testing, assessment, and interventions need to be implemented.

The survey was designed following rigorous methodological approaches informed by Dillman's Tailored Design method. ${ }^{29}$ Our study was conducted on a large, random sample of Canadian emergency physicians. The survey used was optimally developed using key informant and cognitive interviews and subsequently piloted with Ottawa ED physicians. Our study does have potential limitations. It may have been affected by non-response bias due to our $48.3 \%$ response rate. Non-responder answers may be different from those responses actually received, which could affect the generalizability of our results. Although there is a chance of a non-response bias, well-done physician surveys often only achieve response rates of around $50 \%{ }^{30-33}$ The risk strata cut-offs were determined using the 25th percentiles from the distribution of physician responses to satisfy $75 \%$ of physicians. Such cut-offs could be insufficient for up to $25 \%$ of physicians. Our respondents were mainly male physicians (71.8\%) which was in agreement with what was available on the sample frame $(75.3 \%){ }^{34}$

Respondents also came from a variety of training backgrounds and clinical centers, where practice and resource availability may differ, and could possibly influence results. Emergency physicians involved with teaching hospitals represented the majority of respondents, at a combined $92 \%$. This population may be different than the majority of practicing ED physicians in Canada, possibly making our results less generalizable. However, our respondents may actually be representative of Canadian ED physicians. The Canadian Medical Directory we selected 300 physicians from is up-todate, and an appropriate randomization process was followed using computerized randomization. Furthermore, in 1993, a Canadian study reported $65.8 \%$ of Canadian ED physicians surveyed worked in teaching hospitals. Because there are more training positions in rural communities for medical students or residents, it is 
reasonable that this percentage may have increased. Our survey design did not further delineate whether the site was in a large urban setting or within a more rural site, and we did not quantify the number of learners. Finally, there is the possibility of response bias in our respondents. Our rating scales provided equal positive and negative options, but did not include a neutral option, because some more traditional 5- and 7-point Likert scales have. However, our survey design was rigorous in order to discard any potentially leading questions, through the informant and cognitive interviews as well as piloting by Ottawa ED physicians. Finally, at the beginning of the survey, we provided explicit instructions to eliminate any respondents from completing our survey who did not meet our inclusion criteria.

This study demonstrates that Canadian emergency physicians are likely to use a validated Canadian TIA Score. Furthermore, most components of the Canadian TIA Score have high face validity. Risk strata are definable, and physicians are able to agree to clear actions of each risk category.

Competing interests: Authors would like to declare funding from the Canadian Stroke Network Summer Studentship, a grant from the University of Ottawa, Department of Emergency Medicine.

\section{SUPPLEMENTARY MATERIAL}

To view supplementary material for this article, please visit http://dx.doi.org/10.1017/cem.2015.57

\section{REFERENCES}

1. The World Health Organization MONICA Project (monitoring trends and determinants in cardiovascular disease): a major international collaboration. WHO MONICA Project Principal Investigators. 7 Clin Epidemiol 1988;41(2):105-14.

2. Albers GW, Caplan LR, Easton JD, et al. Transient ischemic attack-proposal for a new definition. $N$ Engl 7 Med 2002;347(21):1713-6.

3. Hill MD, Yiannakoulias N, Jeerakathil $\mathrm{T}$, et al. The high risk of stroke immediately after transient ischemic attack: a population-based study. Neurology 2004;62(11):2015-20.

4. Wu CM, McLaughlin K, Lorenzetti DL, et al. Early risk of stroke after transient ischemic attack: a systematic review and meta-analysis. Arch Intern Med 2007;167(22):2417-22.

5. Giles MF, Rothwell PM. Risk of stroke early after transient ischaemic attack: a systematic review and meta-analysis. Lancet Neurol 2007;6(12):1063-72.

6. Gladstone DJ, Kapral MK, Fang J, et al. Management and outcomes of transient ischemic attacks in Ontario. CMAJ 2004;170(7):1099-104.
7. Rothwell PM, Giles MF, Flossmann E, et al. A simple score (ABCD) to identify individuals at high early risk of stroke after transient ischaemic attack. Lancet 2005;366(9479):29-36.

8. Lovett JK, Dennis MS, Sandercock PA, et al. Very early risk of stroke after a first transient ischemic attack. Stroke 2003;34(8):e138-40.

9. Kleindorfer D, Panagos P, Pancioli A, et al. Incidence and short-term prognosis of transient ischemic attack in a population-based study. Stroke 2005;36(4):720-3.

10. Johnston SC, Gress DR, Browner WS, Sidney S. Shortterm prognosis after emergency department diagnosis of TIA. $7 A M A$ 2000;284(22):2901-6.

11. Johnston SC. Editorial comment-transient ischemic attacks are emergencies. Stroke 2005;36(4):724.

12. Perry JJ, Kerr J, Symington C, Sutherland J. How do we manage emergency department patients diagnosed with transient ischemic attack? CFEM 2012;14(1):20-4.

13. Johnston SC. Clinical practice. Transient ischemic attack. $N$ Engl 7 Med 2002;347(21):1687-92.

14. Carandang R, Seshadri S, Beiser A, et al. Trends in incidence, lifetime risk, severity, and 30-day mortality of stroke over the past 50 years. FAMA 2006;296(24):2939-46.

15. Jorm AF, Jolley D. The incidence of dementia: a metaanalysis. Neurology 1998;51(3):728-33.

16. Rosamond W, Flegal K, Furie K, et al. Heart disease and stroke statistics-2008 update: a report from the American Heart Association Statistics Committee and Stroke Statistics Subcommittee. Circulation 2008;117(4):e25-146.

17. Johnston SC, Rothwell PM, Nguyen-Huynh MN, et al. Validation and refinement of scores to predict very early stroke risk after transient ischaemic attack. Lancet 2007;369 (9558):283-92.

18. Shah KH, Metz HA, Edlow JA. Clinical prediction rules to stratify short-term risk of stroke among patients diagnosed in the emergency department with a transient ischemic attack. Ann Emerg Med 2009;53(5):662-73.

19. Ong ME, Chan YH, Lin WP, Chung WL. Validating the $\mathrm{ABCD}(2)$ Score for predicting stroke risk after transient ischemic attack in the ED. Am $\mathcal{F}$ Emerg Med 2010;28(1):44-8.

20. Fothergill A, Christianson TJ, Brown RD Jr, Rabinstein AA. Validation and refinement of the ABCD2 score: a population-based analysis. Stroke 2009;40(8):2669-73.

21. Asimos AW, Johnson AM, Rosamond WD, et al. A multicenter evaluation of the ABCD2 score's accuracy for predicting early ischemic stroke in admitted patients with transient ischemic attack. Ann Emerg Med 2010;55(2):201-10.

22. Sheehan OC, Merwick A, Kelly LA, et al. Diagnostic usefulness of the ABCD2 score to distinguish transient ischemic attack and minor ischemic stroke from noncerebrovascular events: the North Dublin TIA Study. Stroke 2009;40(11):3449-54.

23. Perry JJ, Sharma M, Sivilotti ML, et al. Prospective validation of the ABCD2 score for patients in the emergency department with transient ischemic attack. CMA7 2011;183(10):1137-45.

24. Perry JJ, Sharma M, Sivilotti ML, et al. A prospective cohort study of patients with transient ischemic attack to identify high-risk clinical characteristics. Stroke 2014;45(1):92-100.

25. Sutton M, Grimmer-Somers K, Jeffries L. Screening tools to identify hospitalised elderly patients at risk of functional decline: a systematic review. Int 7 Clin Pract 2008;62(12):1900-9. 
26. Scott's Directories. Canadian Medical Directory. Toronto: Scott's Directories; 2013.

27. Easton JD, Saver JL, Albers GW, et al. Definition and evaluation of transient ischemic attack: a scientific statement for healthcare professionals from the American Heart Association/American Stroke Association Stroke Council; Council on Cardiovascular Surgery and Anesthesia; Council on Cardiovascular Radiology and Intervention; Council on Cardiovascular Nursing; and the Interdisciplinary Council on Peripheral Vascular Disease. The American Academy of Neurology affirms the value of this statement as an educational tool for neurologists. Stroke 2009;40(6):2276-93.

28. Lindsay M, Gubitz G, Bayley M, Phillips S. Hyperacute stroke care. Canadian Best Practice Recommendations for Stroke Care: Canadian best practice recommendations for stroke care. 4th ed. Ottawa: Canadian Stroke Network; 2013.

29. Dillman DA. Mail and Internet surveys: the tailored design method. 2nd ed. Hoboken, NJ: John Wiley \& Sons Inc.; 2007.
30. Perry JJ, Symington C, Mansour M, et al. Is this subarachnoid hemorrhage significant? A national survey of neurosurgeons. Can $\mathcal{7}$ Neurol Sci 2012;39(5):638-43.

31. Perry JJ, Goindi R, Symington C, et al. Survey of emergency physicians' requirements for a clinical decision rule for acute respiratory illnesses in three countries. CFEM 2012;14 (2):83-9.

32. Cummings SM, Savitz LA, Konrad TR. Reported response rates to mailed physician questionnaires. Health Serv Res 2001;35(6):1347-55.

33. Asch DA, Jedrziewski MK, Christakis NA. Response rates to mail surveys published in medical journals. 7 Clin Epidemiol 1997;50(10):1129-36.

34. Canadian Medical Association. Number and percent distribution of physicians by specialty and sex; 2014. Available at: https://www.cma.ca/Assets/assets-library/document/ fr/advocacy/06SpecSex.pdf. 